\title{
Wireless Sensor Network (WSN) for Water Monitoring: A Review on Building Blocks and Factors to Consider During Design Decisions
}

\author{
Kevin Njuu \\ Ardhi University \\ Dar es Salaam, Tanzania
}

\begin{abstract}
Nowadays, WSN based systems have progressively become an important technological advancement. Sensor networks are key in various aspects of life, such as home and industrial automation and health and environmental monitoring. In order to build a sensor based network relevant to a particular application environment, it is important for one to be aware of the current technological developments, as well as available options and techniques in order to make sound decisions. This paper discusses the main building blocks and factors to consider during design decisions of WSN for water monitoring. The paper focuses on the technology alternatives on the WSN subsystems, which are sensing, communication, and storage and processing subsystems. The technological options that are available on each of the subsystems are carefully analyzed and evaluated with regard to the water monitoring application environment. Furthermore, the factors that are important for the development and sustainability of sensor network systems - costs and power sources management are also discussed.
\end{abstract}

\section{General Terms}

Internet of Things, Monitoring Systems

\section{Keywords}

Wireless Sensor Network (WSN), Water Monitoring, WSN Design Decisions

\section{INTRODUCTION}

In recent times, sensor networks are increasingly becoming an important technological means for monitoring of different environmental and physical conditions. They are considered to be the most effective means of collecting real time data, and one of the main contributors towards "Big data" the massive amount of data. Currently, sensor networks are very important in automation and monitoring fields; they are used in various aspects such as home, health, industrial, and environmental monitoring. Usually sensor network consists of several sensing units that are deployed to gather data in the environment at specified time intervals [1]. Researchers around the world are working on improving various aspects of sensor networks such as power consumption, cost reduction, sensing accuracy and transmitting and receiving range. These are not only essential factors for consideration during design of sensor systems, but also very important criteria in evaluating their materiality within an application area. Although it is desirable to have a sensor network function at a low cost and power consumption while maintaining performance and remote flexibility, optimizing each of these aspects may be contradictory to each other. The major challenge is to build the right system right, which is ensuring for efficiency and effectiveness at an optimal tradeoff between the two. Therefore, the purpose of this paper is to review the main building blocks and factors for consideration during WSN design and implementations for water monitoring application context. The building block includes the sensing subsystem, communication subsystem and storage and processing subsystem, while factors for consideration are the costs and power sources management.

\section{THE BUILDING BLOCKS OF WSN FOR WATER MONITORING}

There are various techniques for liquid level sensing, however, identifying the most appropriate one that is suitable for a particular application can be very challenging and time consuming. This segment discusses the major techniques for liquid level sensing, theory behind them and their advantages and disadvantages. The first technique is the use of ultrasonic based measurements [2] the ultrasonic works by exerting high frequency sound signals that are bounced back and detected. The time taken by the signal to travel from the sensor face to the target and back is related to the liquid level. Ultrasonic based measurements are carried out without touching the liquid that is being monitored and the technique is fitting for a variety of liquids. However ultrasonic based measurements are not appropriate for implementation in high pressure environments and requires a healthy reflection of sound waves from the liquid being measured [3]. [4] and [5] have indicated the applications of ultrasonic based methods for rivers flow measurements. A second technique is by the use of radar method, sometime referred as microwave whereby a pulse of radiation is transmitted to the surface and some proportion is reflected back the same way as the ultrasonic based level measurements. The fundamental difference between radar and ultrasonic method is the type of wave used; radar uses radio waves instead of sound waves used in ultrasonic. Thereafter, with a relatively refined electronic setup, it is possible to measure the transit time because the speed of the wave is a known constant, the distance can be derived as stipulated in [6] and [3]. This technique is simple to setup and can be used with solids and liquids although it is usually an expensive option [2]. Hydrostatic pressure is another technique that is based on the premise that fluids emit pressure that correlated to height. This technique can be used to determine liquid levels in different settings such as in a tank [7]. A pressure sensor is usually deployed in such a way that one side connected to the pipe and the other side is exposed to the atmospheric pressure. Then the sensor gauges the difference in pressure which coincides with the change in the tank liquid level. This method is appropriate for implementations containing vapour, foam or any agitation, but restricted to implementations with low viscosity liquids with particular range of measurement [2]. Capacitive sensors is yet another 
method for measuring liquid levels Using low radio frequency to evaluate conductivity of current in a closed circuit that differs in proportion to the application level. It is a function of the fluid's dialectic constant, the capacitor's surface area, the probe and the separation distance [2]. It is typically used in applications where it is necessary to measure the amount of solids, liquid metal, corrosive materials etc. [8]. Liquid levels can also be tracked in rivers and reservoirs by measuring the electrical capacity in the liquid between two electrodes. Its benefits are it consumes low power, it is cheap (i.e. sensors can be constructed using inexpensive techniques), high linearity and works well with both the liquids and solids [9]. However, due to the fact that capacitance is a contact based measurement system, is not always suitable for use with sticky fluids. Works by [8] and [9] depict typical applications of capacitive based liquid level measurements. Table 1 summarizes techniques for liquid level measurements. There are various communication technologies that are available nowadays. There is no ideal technology and each constitutes a compromise between various variables such as data rate, cost, coverage, power consumption, etc. Therefore choosing a specific technology relies on the application environments. [10]. Wired sensor networks are not only very reliable but stable communication option. Although you can connect sensors

using

Table 1: Summary of liquid level measurement techniques

\begin{tabular}{|c|c|c|c|c|}
\hline $\mathbf{S} / \mathbf{N}$ & Techniques & How it works & Advantages & Disadvantages \\
\hline 1. & $\begin{array}{l}\text { Ultrasonic based } \\
\text { method }\end{array}$ & $\begin{array}{l}\text { Emits high frequency acoustic signals } \\
\text { that are reflected back and detected. } \\
\text { The time taken by the signal to travel } \\
\text { from the sensor face to the target and } \\
\text { back is related to liquid level }\end{array}$ & $\begin{array}{l}\text { Measurements taken } \\
\text { without physical } \\
\text { contact and suitable } \\
\text { for a wide range of } \\
\text { liquids and bulk } \\
\text { products }\end{array}$ & $\begin{array}{l}\text { Unsuitable for highly } \\
\text { pressurised, high turbulence } \\
\text { or applications with steam } \\
\text { or foam. Requires a healthy } \\
\text { reflection of sound waves } \\
\text { from the liquid being } \\
\text { measured }\end{array}$ \\
\hline 2. & $\begin{array}{c}\text { Radar } \\
\text { (microwave) } \\
\text { method }\end{array}$ & $\begin{array}{l}\text { Works the same way as ultrasonic. The } \\
\text { fundamental difference is that radar } \\
\text { uses radio waves instead of sound } \\
\text { waves used in ultrasonic }\end{array}$ & $\begin{array}{l}\text { Easy to install, can be } \\
\text { used with liquids and } \\
\text { solids. Not affected } \\
\text { by emulsification, } \\
\text { dust, foam }\end{array}$ & Usually an expensive option \\
\hline 3. & $\begin{array}{l}\text { Hydrostatic } \\
\text { pressure method }\end{array}$ & $\begin{array}{l}\text { Based on the principle that fluids exert } \\
\text { pressure that is a function of height. }\end{array}$ & $\begin{array}{l}\text { Suitable for } \\
\text { applications that } \\
\text { contain vapour, foam } \\
\text { or any form of } \\
\text { agitation }\end{array}$ & $\begin{array}{l}\text { Limited to applications with } \\
\text { low viscosity liquids and } \\
\text { with a specific measuring } \\
\text { range }\end{array}$ \\
\hline 4. & $\begin{array}{l}\text { Capacitive based } \\
\text { method }\end{array}$ & $\begin{array}{l}\text { Measures conductivity of current in a } \\
\text { closed circuit that varies proportionally } \\
\text { to height. It is a function of dialectic } \\
\text { constant of the fluid, the surface area of } \\
\text { the capacitor and the separation } \\
\text { distance }\end{array}$ & $\begin{array}{l}\text { Low-cost, low power } \\
\text { consumption, high } \\
\text { linearity and works } \\
\text { well with both the } \\
\text { liquids and solids }\end{array}$ & $\begin{array}{l}\text { Capacitance is a contact } \\
\text { based measurement not } \\
\text { always suitable for use with } \\
\text { sticky fluids }\end{array}$ \\
\hline
\end{tabular}

a wired network, often sensors are expected to work in environments where running wires is not possible. On the other hand, Wireless sensor networks are feasible and possible for deployments in areas were running of cables is a challenge. Implementations of WSN are also arguably cheaper than the wired ones. [11].This is why the application of WSN usually is a better option over the use of cabled sensors. Most importantly, sensor networks require use of wireless technology, a more versatile medium of data exchange between communicating entities in a network [12]. One form of wireless communication is a Wi-Fi (IEEE 802.11), a versatile protocol for data communication introduced to complement or replace wired local area network technologies such as Ethernet [13]. Although this protocol is usually utilized in computer based networks, it is possible to create WSN with it, however higher power consumptions makes battery use infeasible and remains a major disadvantage for use within WSN. Another short range form for wireless communication standard is Bluetooth (IEEE 802.15.1) [13]. It is considered a cable replacement for mobile devices. Although Bluetooth-based devices are designed to support Wireless Personal Area network (WPAN), usually they are capable of operating at higher distances of up to 10 meters of [14]. Some of its popular tasks are data transmission and synchronization, e.g. between a mobile device and a computer [11]. Therefore for applications requiring high data rates over short distances, Bluetooth remains the best technology [15]. On the other hand, Bluetooth is probably the nearest possible option for use in WSNs, but the fact that its power consumption has not been primary priority in its design, makes it unsuitable for applications that require ultralow power consumption. There is yet another form of wireless communication at our disposal, the Zigbee (IEEE 802.15.4) technology. It is low power consumption, cheap and low data rate standard aimed at automation and remote control systems implementations [16]. It prioritizes power management as it was created for implementations requiring low power consumption and years of battery life. It supports lower data rates than Bluetooth. It can transmit up to 10 meters between walls while outside transmission range can be up to 200 meters. However the actual distance is dependent on the transmission power [17]. Zigbee networks are useful, relatively low-cost option for obtaining high quality data [1], it therefore an ideal option for building networks larger than with Bluetooth and supports several topologies The work by [4] clearly demonstrates Zigbee based WSN to be scalable, 
very low power consuming and can operate in harsh environments. Table 2 summarizes comparison between

different wireless standards.

Table 2: Comparison between Wi-Fi, Bluetooth and ZigBee.

\begin{tabular}{|c|c|c|c|c|}
\hline $\mathbf{S} / \mathbf{N}$ & Feature & $\mathbf{W i}-\mathbf{F i}$ & Bluetooth & ZigBee \\
\hline 1 & Standard & IEEE $802.11 \mathrm{~b} / \mathrm{g} / \mathrm{n}$ & IEEE 802.15 .1 & IEEE 802.15.4 \\
\hline 2 & Data rate & $11 / 54 / 320 \mathrm{Mb} / \mathrm{s}$ & $1-2 \mathrm{Mb} / \mathrm{s}$ & $250 \mathrm{~Kb} / \mathrm{s}$ \\
\hline 3 & Coverage & A building & $\begin{array}{l}\text { Personal area network (usually } \\
\text { 10m). Although can transmit } \\
\text { greater distances. }\end{array}$ & $\begin{array}{l}\text { Up to } 30 \mathrm{~m} \text { indoor, } 1000 \text { outdoor } \\
\text { depending on transmission } \\
\text { power. }\end{array}$ \\
\hline 4 & $\begin{array}{c}\text { Power } \\
\text { consumption }\end{array}$ & $\begin{array}{c}\text { Higher (Battery last in } \\
\text { hours) }\end{array}$ & High (Battery could last in Days) & Low (Period of weeks to a year) \\
\hline 5 & Costs & High & Average & Low cost \\
\hline 6 & Applicability & $\begin{array}{l}\text { Computer based } \\
\text { networks }\end{array}$ & $\begin{array}{c}\text { Exchanging data between mobile } \\
\text { devices and Computer }\end{array}$ & Wireless sensor networks \\
\hline
\end{tabular}

On the other hand, data collected by sensors can be uploaded to a cloud or web server. That way it can be conveniently accessed and retrieved from anywhere at any time with reliable internet access. Therefore, connecting sensor networks to the internet will give additional value of remote flexibility. ZigBee and Bluetooth sensor networks can integrate with other networks such as Global System for Mobile Communication (GSM), General Packet Radio Service (GPRS), Enhanced Data Rate for GSM (EDGE) and $3 \mathrm{G}$ and $4 \mathrm{G}$ technologies to create wide area wireless coverage $[18,19]$. The GSM standard was created to provide a prevalent technology of the second generation for Europe [16]. Presently it is available even in rural and harsh environments and arguably the most widely used communication technology in the globe. Furthermore it is a circuit-switched network working at $900 \mathrm{MHz}$ and $1800 \mathrm{MHz}$ bands and regarded among the safest communication standards [20]. These attributes are making it very suitable technology for remote monitoring applications. For example, with GSM, notifications and even controls of things can be implemented in form of text messages. [21] Proposed a water pollution monitoring system that uses GSM to send an automated Short Message Service (SMS) alerts. The downside of GSM is that it takes long time to set-up a connection while data transmission rates may be insufficient for applications requiring higher data rates.

GPRS is another technology that can be deemed a significant improvement of the GSM [22]. It provides decreased connection set-up duration and better data transfer speed compared to GSM [23]. It supports IP-based applications across GSM network because it allows packet-based transfer of information across the circuit-based GSM network. [20]. It is often combined with short distance communication technologies such as ZigBee to form a remote sensor network. [17] and [4] Proposed systems to remotely and automatically monitor meter readings using GSM and ZigBee. EDGE is another significant increase in data rates for GSM which is designed in such a way that it offers higher performance levels [22]. 3G technology exploits the benefits of earlier cellular and internet technologies for communication [24]. 3G networks strive to provide ubiquitous access to multimedia services [25] making it ideal for applications that require higher data rates. However, its power consumption and coverage in remote areas is of great concern.

Because of resource limitations and processing demands, decisions for sensor data storage involve deciding on what data to be stored, possible locations for storing and for how long to store. Several methods have been suggested for storing data collected by sensor networks. The first approach is the local storage where data is being stored at the sensing node particularly by using the SD cards. This method is used in situations where sensor nodes are designed with no connectivity to other nodes or intended as a backup storage in case of connection problems between the sensing node and the central storage [12]. Nodes with this type of storage are often power efficient because sending of data consume a great deal of energy. Moreover sensor data for some long time can be stored since the capacity of storage devices such as SD card is no longer a challenge. However the primary disadvantage of this method is that, it demands for manual visits to the sensor nodes to offload data and thus not suitable for places where visits are not possible, feasible or dangerous. Another approach is the remote storage or base station storage where all data is stored and processed in a centralized manner. For example, storing data on a different node usually sink node or server connected to the internet. This usually needs some type of remote storage communication or network connectivity to the remote storage $[12,26]$. This approach has the benefit of allowing a friendly centralized access to data at any time and from anywhere provided internet connection is available. Sensor nodes, however, will quickly deplete energy for continuous transmitting data to the central system.

The hybrid approach is another mechanism for sensor network data storage whereby a combination of both local and remote storage is applied. Although this option consumes more resources, it provides a more solid and reliable data storage design. The local and remote storages can be used as a backup for each other to ensure data is not lost in the event of any problem happening with either the storages or the communication system itself. Table 3 provides a comparison summary of data storage alternatives while Table 4 provides comparison between local and remote data processing. 
Table 3: Comparison of storage locations for sensor data

\begin{tabular}{|c|c|c|c|}
\hline $\mathbf{S} / \mathbf{N}$ & Storage location & Advantage & Disadvantage \\
\hline 1 & $\begin{array}{l}\text { Local storage only i.e. } \\
\text { at sensing node. }\end{array}$ & $\begin{array}{c}\text { Less complicated } \\
\text { More power efficient as sending } \\
\text { consumes more energy }\end{array}$ & $\begin{array}{l}\text { Require manual visits to site offload data. } \\
\text { High risk of losing data /no backup } \\
\text { Difficult to monitor data logging }\end{array}$ \\
\hline 2 & $\begin{array}{l}\text { Remote storage only } \\
\text { i.e. at the centralized } \\
\text { database }\end{array}$ & $\begin{array}{l}\text { Possible to remotely monitor data logging } \\
\text { Easy to notice failure } \\
\text { Friendly centralised data with real time } \\
\text { access }\end{array}$ & $\begin{array}{l}\text { Sensor nodes will quickly deplete energy for } \\
\text { continuous reporting and transmitting data } \\
\text { The high risk of losing/missing data during } \\
\text { sending in case of failure }\end{array}$ \\
\hline
\end{tabular}

Table 4: Sensor data processing location comparison

\begin{tabular}{|c|c|c|c|}
\hline $\mathbf{S} / \mathbf{N}$ & Processing Location & Advantage & Disadvantage \\
\hline 1 & $\begin{array}{l}\text { Local processing only } \\
\text { i.e. at sensing node. }\end{array}$ & $\begin{array}{l}\text { Processing of single node data is less } \\
\text { complicated. }\end{array}$ & $\begin{array}{l}\text { Possible only for lightweight processing } \\
\text { requirements. } \\
\text { Require additional components at each node } \\
\text { of which increases cost. } \\
\text { Loss of raw data which could be used for } \\
\text { other purposes. }\end{array}$ \\
\hline 2 & $\begin{array}{l}\text { Remote processing } \\
\text { only i.e. at the } \\
\text { centralized database }\end{array}$ & $\begin{array}{l}\text { More organised and centralized } \\
\text { processing. } \\
\text { Reduce cost (the centralized processing) } \\
\text { Easy to notice failure }\end{array}$ & $\begin{array}{l}\text { Require more sophisticated processing } \\
\text { system capable of handling data for } \\
\text { different sensor nodes separately and } \\
\text { accordingly }\end{array}$ \\
\hline
\end{tabular}

\section{FACTORS TO CONSIDER DURING DESIGN OF WSN FOR WATER MONITORING.}

Up to now, energy sources has been the major limiting factor in sensor networks [27]. While latest technological advances have helped to reduce electronic device power consumption, the ration between the energy that can be stored in present energy storage devices and electronic circuitry power consumption limits the lifespan of the system. In addition, a WSN deployment lifespan relies on the type and nature of activities being monitored. High data rate applications can last for a few days whereas applications requiring reduced data rates and can attain longer life for the same amount of energy plan.[28]. The basic way for powering sensor node is a battery. Despite recent significant improvements, batteries still Have a restricted lifespan and costly to maintain and therefore not a sustainable long-term energy source for sensor networks [29]. In addition, it is hard to replace or recharge batteries in certain applications [30]. There are, however, several works that have effectively used batteries as a energy source including the work by [4] that uses Lithium Thionyl Chloride batteries with specifications of $3.6 \mathrm{~V}$ and $14 \mathrm{mAh}$ to power their smart water discharges meter for a period of up to 5 years. This extra low power design is highly contributed by the development of own PCB (Printed Circuit Board) that uses products with Microchip's Nano Watt XLP (Extra Low Power) technology. Another way of powering sensing nodes that has recently attracted attention are systems that can obtain energy from the environment[31]. Since sensor networks are mostly used in outdoor environments, it is possible to collect energy from sources like sunlight, water flow, wind, etc. These characteristics can be exploited to increase sensor network lifetime. However, it is sometimes not feasible to use energy from the environment rather than batteries because environmental circumstances are sometimes unstable and unpredictable Therefore a combination of an energy harvesting techniques with rechargeable battery can be implemented for the WSN. Batteries can directly be recharged onsite by using energy from the environment. Hybrid energy sources improve the likelihood of continuous power supply because each source can compensate for some energy fluctuation on its counterpart. [30]. The work by [32] on an energy efficient sensor network system for environments with restricted energy sources is a good depiction of this technique. Despite the fact that sensor networks are no longer costly. They can be designed from readily available and low-cost hardware components [12], companies around the globe are still offering off-the-shelf solutions that are even more expensive. Low-cost sensor network for collecting high quality data can be designed and built locally. Skilled personnel are nowadays easily available. Moreover the knowledge is increasingly becoming common and skills can easily be developed. However, the choice to construct inhouse or to use off -the-shelf alternatives is a complicated trade-off between different variables such as information sensitivity, time and price [1]. The uses of open source software and hardware platforms offer opportunity for lowering costs and effort over the proprietary platforms. They are low power, low-cost and are more reliable approach providing full control and flexibility of future maintenance. This is because of the assistance of different platforms where individuals share and profit from their combined commitments. The work presented by [33]for monitoring farmers irrigation practise is a low-cost solution for American small scale farmers but for the case of smallholder farmers in 
developing Sub-Saharan countries, the cost is still not affordable. This brings the fact that the cost of WSN as applied in different application environments is typically relative and should be kept in the mind of design engineers. Taking this fact into consideration could be the first step towards introduction of WSN solutions or products targeted and tailored for different user groups like in the case of other information technology (IT) related products such as mobile phones and computers. On the other hand, the low-cost of [4]smart meter for river water discharges is claimed to have been contributed by the use of annually replaceable batteries that have significantly reduced costs by replacing the use of solar panels, but the fact that costs for solar panels are only one time and nowadays can be procured cheaply and easily, it is therefore challenging to conclude which is the cheaper option. Therefore, it is important to conduct a systematic costbenefit analysis between solar panel costs and the cost for periodic replacement of the batteries for a particular application context before making the final decision for the cheaper option. Therefore, while making design decisions, it is important to address the budget of sensor network in terms of both onetime initial costs as well as ongoing costs such as maintenance costs. It is always unrealistic that, the maintenance costs are far higher that the initial installation costs, thus during design decisions, it is very important that this factors are carefully analysed and addressed.

\section{CONCLUSION}

This paper looked at the developments in WSN for water monitoring building blocks. The main focus was on technological options available on each of the WSN subsystems. The paper also discussed factors to consider during design decisions such as costs and power sources. Although not discussed in this paper, software and hardware security is also a key factor for consideration during the design of systems destined for real environment operations. Physically securing of sensing components is challenging and tend to significantly add to the costs. Issues of security and protection from environmental conditions tend to cost more than the actual cost of the components. Therefore, it is important to innovate low-cost component combinations as well as physical and weather protections that will significantly reduce the risk of financial losses, while keeping in mind that the applications of participatory approaches have been witnessed to have reduced risk of financial losses to some great extent.

\section{REFERENCES}

[1] Watras, C.J., et al., Evaluation of wireless sensor networks (WSNs) for remote wetland monitoring: design and initial results. Environmental monitoring and assessment, 2014. 186(2): p. 919-934.

[2] Process Industry Forum. Tutorial on level measuring techniques for liquids and fluids. 2013 [cited 20158 March]; Available from: http://www.processindustryforum.com/article/tutoriallevel-measuring-techniques-liquid-fluid.

[3] Instrumentation toolbox. Ultrasonic level sensorsOperating principles. 2015 [cited 20158 march]; Available from: http://www.instrumentationtoolbox.com/2013/07/ultraso nic-level-sensors-operating.html\#axzz3Tg0tHD8Y.

[4] Ahmad, Z., et al., Development of a low-power smart water meter for discharges in indus basin irrigation networks, in Wireless Sensor Networks for Developing Countries. 2013, Springer. p. 1-13.

[5] Rowe, M., L. Fry, and J. Mihelcic. Low-Cost Sensor Network for Stream Flow Monitoring in the Alto Beni Region of Bolivia. in AGU Fall Meeting Abstracts. 2009.

[6] Boyes, W., Instrumentation reference book. 2009: Butterworth-Heinemann.

[7] Nikolov, G. and B. Nikolova, Virtual techniques for liquid level monitoring using differential pressure sensors. RCENT, 2008. 9: p. 2.

[8] Mathews, S.C., K. Thattai, and P.K. Ramanathan, Design and Development of a Simple and Efficient Low Cost Embedded Liquid Level Measurement System. 2013.

[9] Reverter, F., X. Li, and G.C. Meijer, Liquid-level measurement system based on a remote grounded capacitive sensor. Sensors and Actuators A: Physical, 2007. 138(1): p. 1-8.

[10] Fourty, N., et al. Comparative analysis of new high data rate wireless communication technologies" From Wi-Fi to WiMAX". in Autonomic and Autonomous Systems and International Conference on Networking and Services, 2005. ICAS-ICNS 2005. Joint International Conference on. 2005. IEEE.

[11] Ruiz-Garcia, L., et al., A review of wireless sensor technologies and applications in agriculture and food industry: state of the art and current trends. Sensors, 2009. 9(6): p. 4728-4750.

[12] Bell, C., Beginning Sensor Networks with Arduino and Raspberry Pi. 2013: Apress

[13] Wang, N., N. Zhang, and M. Wang, Wireless sensors in agriculture and food industry-Recent development and future perspective. Computers and electronics in agriculture, 2006. 50(1): p. 1-14.

[14] Shuaib, K., et al. Co-existence of Zigbee and WLAN, a performance study. in Wireless Telecommunications Symposium, 2006. WTS'06. 2006. IEEE.

[15] Kooker, J., Bluetooth, zigbee, and wibree: A comparison of wpan technologies. CSE 237A, November, 2008. 20.

[16] Garg, V., Wireless Communications \& Networking. 2010: Morgan Kaufmann.

[17] Quan-Xi, L. and L. Gang. Design of remote automatic meter reading system based on ZigBee and GPRS. in Proceedings of the Third International Symposium on Computer Science and Computational Technology (ISCSCT'10). 2010.

[18] Eddabbah, M., M. Moussaoui, and Y. Laaziz, A flexible 3G WebService Based Gateway for Wireless Sensor Networks in support of Remote Patient Monitoring Systems. 2015.

[19] Usman, A. and S.H. Shami, Evolution of communication technologies for smart grid applications. Renewable and Sustainable Energy Reviews, 2013. 19: p. 191-199.

[20] Balaji, R. and R. Ganesan, Remote Water Pollution Monitoring System Using GSM. International Journal of Computer Science and its Applications, 2012. 
[21] Wesolowski, H. and K. Wesolowski, Mobile communication systems. 2001: John Wiley \& Sons, Inc.

[22] Arshad, M.J., A. Farooq, and A. Shah, Evolution and development towards 4th generation (4G) mobile communication systems. Journal of American Science, 2010. 6(12): p. 63-68

[23] Shaikh, F.K., et al. Wireless Sensor Networks for Developing Countries. in First International Conference, WSN4DC. 2013. Springer.

[24] El Barachi, M. and O. Alfandi. The design and implementation of a wireless healthcare application for WSN-enabled IMS environments. in Consumer Communications and Networking Conference (CCNC), 2013 IEEE. 2013. IEEE.

[25] Ai, C., et al., In-network historical data storage and query processing based on distributed indexing techniques in wireless sensor networks, in Wireless Algorithms, Systems, and Applications. 2009, Springer. p. 264-273.

[26] Park, C. and P.H. Chou. Ambimax: Autonomous energy harvesting platform for multi-supply wireless sensor nodes. in Sensor and Ad Hoc Communications and Networks, 2006. SECON'06. 2006 3rd Annual IEEE Communications Society on. 2006. IEEE.
[27] Castagnetti, A., et al., A framework for modeling and simulating energy harvesting wsn nodes with efficient power management policies. EURASIP Journal on Embedded Systems, 2012. 2012(1): p. 1-20.

[28] Nechibvute, A., A. Chawanda, and P. Luhanga, Piezoelectric energy harvesting devices: an alternative energy source for wireless sensors. Smart Materials Research, 2012. 2012.

[29] Akbari, S. Energy harvesting for wireless sensor networks review. in Computer Science and Information Systems (FedCSIS), 2014 Federated Conference on. 2014. IEEE.

[30] Ševcík, P. and O. Kovár. Alternative energy sources for WSN node power supply. 2013. ITS.

[31] Semente, R.S., et al. A energy efficient WSN system for limited power source environments. in Proceedings of 7th International Conference on Sensing Technology (ICST). 2013

[32] Kinzli, K.-D., A low cost remote monitoring method for determining farmer irrigation practices and water use 2012, INTECH Open Access Publisher. 